\title{
К ВОПРОСУ О МОДИФИКАЦИИ СТРУКТУРНЫХ СДВИГОВ В ПРОЦЕССЕ РАЗВИТИЯ КОНВЕРГЕНТНЫХ ТЕХНОЛОГИЙ
}

\author{
(c) 2019 Таран Екатерина Александровна \\ старший преподаватель, Школа инженерного предпринимательства, \\ Национальный исследовательский Томский политехнический университет, Россия, Томск \\ E-mail: ektaran@tpu.ru
}

В статье рассмотрено воздействие экспансии конвергентных технологий на развитие воспроизводственной системы, модифицирующее структурные сдвиги в экономике. Определены глобальные сетевые кластеры конвергентных технологий. Выявлено новое содержание структурных сдвигов, вызванное радикальным обновлением технологического базиса воспроизводства конвергентного типа, инициирующим имманентный ему принцип структуроформирования в экономике.

Ключевые слова: структурный сдвиг, конвергентные технологии, сетевые кластеры, технологическая конвергенция, релокация производительных сил

На современном этапе развития конвергентные технологии играют одну из главных ролей в процессе модификации структурных сдвигов. Они ускоряют воспроизводственные процессы, соединяют инновационное развитие разных секторов экономики, диверсифицируют промышленное производство и экспорт, при условии их массового межотраслевого трансфера, сетевой релокации производительных сил, институциональной минимизации рисков инвестирования инноваций. Происходит становление конвергентного типа развития воспроизводства, сопровождаемого взаимопроникновением автономных научно-инновационных, инвестиционных, социально-экономических взаимосвязей.

Для проведения исследования был использован комплекс методов современной экономической науки, а именно, системный, причинно-следственный логический анализ. Это позволило выделить основные глобальные сетевые кластеры конвергентных технологий, а также определить роль конвергентных технологий в процессе релокации производительных сил, в основе которой лежит модификация экономических отношений в системе национального воспроизводства.

Исследование роли конвергентных технологий в развитии современной экономики в большей степени сегодня осуществляется с точки зрения технократического подхода. При этом анализу воспроизводственных отношений, посредством которых технологическая конвергенция создает структуро-преобразующие производительные силы и модифицирует экономические отношения, уделяется недостаточное внимание. Так, первоначально технологическая конвергенция стала объектом социологических исследований в 1990-х гг. (М. Кастельс[8]). Позже М. Роко и У. Бейнбридж[13] определили конвергентные технологии как синергетический результат взаимодействия представителей четырех сфер отраслевой науки - нано- и вычислительных технологий, генной инженерии, нейронауки. С 2001 г. под эгидой Национального научного фонда США была выдвинута так называемая NBIC (НБИК)-инициатива (нанотехнологии-биотехнологии-IT-когнитивные науки), которая обозначает некое конвергентное целое [3]. Связь технологической конвергенции с развитием национальной инновационной системы рассматривалась И.А.Елхиной [6] как соединение изолированных траекторий отраслевого инновационного развития, а М.А. Гасановым и Э.А. Гасановым - как интеграция инновационных процессов в базовых и высокотехнологичных отраслях на основе дигитализации (структурно-технологическая конвергенция) [4].

Согласно авторскому подходу, технологическая конвергенция это процесс трансформации структуры экономики, инициируемый соединением развития экономических отношений в воспроизводственной системе (новые формы инвестирования инноваций и новые источники капитала, модификации соединения факторов производства) и слияния технологий в новом структурном генезисе. С точки зрения развития производительных сил, технологическая кон- 
вергенция означает новую их релокацию. Такая релокация происходит в виде формирования глобальных сетевых кластеров конвергентных технологий, использующих практически неограниченные источники инвестиций глобального рынка капитала и цифровизованный рынок высокоинтеллектуального труда, создающих продукты, существующие преимущественно в нематериальной форме, экстерриториально создаваемые и потребляемые.

В свою очередь, конвергентно-технологическая релокация производительных сил неотъемлема от модификации экономических отношений в воспроизводственной системе. Возникают новые формы привлечения капитала (IPO высокотехнологичных компаний, краудфандинг, государственно-частные высокотехнологичные партнерства) и инвестирования инноваций (инновационное интрапренерство, со-инвестирование разработчиков и потребителей). Формируются новые взаимосвязи предпринимательских структур - инвесторов, разработчиков технологий, собственников ресурсов и готового продукта (блокчейн, «умный контракт»). В результате труд и капитал становятся настолько мобильными, что износ средств производства стремится к нулю, а работники постоянно повышают свои компетенции в процессе комбинирования технологий. В такой системе релокации производительных сил и модификации экономических отношений новые отрасли создаются конгруэнтно переплетению технологий.

Релокационная и модификационная роль конвергентных технологий объясняется их инновационно-диффузной сущностью, что делает невозможным создание единого центра. Напротив, их кластеры образуют собой полицентричную сеть, в которой происходит постоянный обмен ноу-хау и совместное патентование прорывных инноваций, внедрение которых постепенно принимает повсеместный характер. Проведенный анализ источников литературы, позволяет выделить четыре основных глобальных кластерах конвергентных технологий:

Глобальный кластер нанотехнологий (производства супер-микрообъектов размером в несколько нанометров (10-9) м из отдельных молекул, количество которых может достигать десятков тысяч), в котором создаются такие блага, как материалы с новыми свойствами, медицинские препараты «полного здоровья», реагенты полного цикла переработки сырья и снижения энергопотребления и пр. Примерами европейских сетевых «узлов» глобального кластера нанотехнологий можно считать итальянский «Veneto Nahotech», французский «Minalogic», занятыми в нанофабрикации электронных устройств, создании встраиваемых «систем на кристалле», новых природоохранных реагентов [1].

Кластер биотехнологий осуществляет диффузию инноваций, связанных с решением новых технологических задач в отраслях здравоохранения, малой энергетики, пищевых производств, информатики, при помощи живых организмов и продуктов их жизнедеятельности. Релокация производительных сил, обеспечивающих развитие биотехнологий и их промышленное применение, связана с такими тесно взаимодействующими кластерами, как шведско-датский «Medicon Valley», швейцарский «BioValley», французский «Paris BioClast», испанский «Catalonia BioRegion». Роль государства как партнера некоммерческих организаций и частного бизнеса заключается в предоставлении налоговых стимулов для объединения финансирования наиболее прорывных и перспективных разработок [12].

Релокация производительных сил в кластерах суперсовременных нано- и биотехнологий, равно как и взаимосвязей между их субъектами осуществляется в форме конвергенции «нано-био», в которой происходит формирование рынка новых товаров и услуг - биосенсоров и биодетекторов для здравоохранения и медицины, самогенерерующих искусственных комплексов, микропроцессоров с биомолекулами и протеинами для сферы информационных технологий. Глобальным результатом развития взаимодействий между кластерами конвергентных нано- и биотехнологий на 2014 г. стало производство инновационных благ более чем на 1 трлн. долл. и создание порядка 300 тыс. рабочих мест более чем в 30 странах мира [11].

Глобальный сетевой кластер конвергентных информационных технологий развивается формируется в процессе цифровизации традиционных секторов экономики - базовых и обрабатывающих отраслей, образования и здравоохранения, транспорта и связи, образования и медицины, обороны и национальной безопасности, государственного управления. Релокация производительных сил такого глобального кластера идет практически повсеместно в 
технологически развитых странах (IT-кластеры Бангалор в Индии и Далян в Китае, «Кремниевая Долина» в США, российский «Сколково» и пр.).

В такой кластеризации модифицируется создание стоимости конвергентных информационных благ. Поскольку до 60\% компьютерных программ разрабатывается сегодня другими программами («облачное», или «распределенное программирование»), то денежная форма стоимости постепенно заменяется блокчейном (блоками транзакций), а по мере конвергентного слияния информационных технологий и материального производства альтернативные транзакции расширяют сферу применения, создавая еще больший спрос на новые информационные блага.

В результате рынок информации, в том числе как средства производства («облачных» программных продуктов) достиг в 2017 г. 3,4 трлн. долл., мировой рынок блокчейна (не считая криптовалют) - 400 млн. долл. В целом капитализация мировой IT-индустрии оценивается в 1,2 трлн. долл., а вклад в глобальную занятость в 3,5\% от всех рабочих мест, при этом данные рабочие места создаются в подавляющем большинстве в негосударственном секторе экономики. В странах с высокой долей IT-сектора в экономике (Сингапур, Япония, Нидерланды - до $15 \%$ от ВВП) $[2,5]$ цикличный рост капитализации фондового рынка сокращается с 10-12 до 6-7 лет, что свидетельствует о значительных отличиях будущей экономической динамики стран с высоким уровнем развития когнитивных технологий от стран с доминированием базовых отраслей.

Глобальный сетевой кластер когнитивных технологий - результат релокации информационно-вычислительных, интеллектуальных, производственных ресурсов, занятых в создании средств производства 21-го века - систем искусственного интеллекта. Вклад данного кластера в технологическую модернизацию экономики по мере развития грядущего - 6-го технологического уклада - заключается в развитии принципиально новых средств производства (безлюдных систем, сверхпроизводительных компьютеров, способных обеспечить высокоточное производство материальных благ). Концентрация инновационной активности по разработке когнитивных технологий имеет место в США (Центр Когнитивных Технологий Google, ATT Cognitive Research, Cognitive Industries Inc и др.).

Несмотря на сравнительно небольшие объемы мирового рынка готовых когнитивных технологий (11 млрд. долл. в 2016 г., по оценкам компании IBM [10], именно они будут определять т.н. «пост-шестой» технологический уклад и будущий этап промышленного развития «Индустрия 5.0», в основе которого будет широкое применение «сильного» искусственного интеллекта и «информационных клонов мозга». Поэтому сегодня основными инвесторами когнитивных технологий выступают крупнейшие мировые корпорации в IT-сфере (Apple, Google, Microsoft с суммарной капитализацией в 2,4 трлн. долл.). По экспертным оценкам, порядка 5-7\% от инвестиционных бюджетов данных корпораций, или 11 млрд. долл., ежегодно направляется на разработку фундаментальных когнитивных технологий будущего [9].

Релокация производительных сил в кластерах информационных и когнитивных технологий происходит в форме конвергенции «инфо-когно», с созданием и рыночной коммерциализацией вычислительных технологий, значительно автоматизирующих процессы создания новых программных продуктов с одной стороны (программирование без ошибок, информационные системы с гарантированной надёжностью, проектирование искусственного интеллекта), с другой - совершенствующих системы управления в сферах производства и распределения (заводов, банков, инвестиционных фирм), государственного управления. Конвергенция «инфо-когно», по оценкам «РБК», приведет к почти пятикратному росту рынка IT-технологий к 2040 г. (до 15 трлн. долл.), что сделает его самым крупным глобальным рынком [7].

Диффузия конвергентных технологий сопряжена с модификацией экономических отношений в инвестиционной, инновационной, кредитной сферах, в отраслевом производстве, с преобразованием отношений собственности. Совокупность процессов модификации экономических отношений в воспроизводственной сфере создают условия для структурного сдвига нового типа, в котором структуро-образующим фактором выступает не создание и коммерциализация новых отраслевых технологий, а их взаимное переплетение. Структурный сдвиг представляет собой необратимый комплекс изменений во всех видах структуры экономики. Данные изменения возникают в процессе мо- 
дификации экономических отношений, в совокупности важнейших институтов, в воспроизводственной системе, выступают толчком для качественного скачка основных макро- и мезоэкономических пропорций.

Структурный сдвиг, вызванный технологической конвергенцией, означает, прежде всего, релокацию производительных сил, в основе которой лежит модификация экономических отношений в системе национального воспроизводства, связанная с появлением новых форм привлечения капитала (IPO высокотехнологичных компаний, краудфандинг, высокотехнологичные государственно-частные партнерства) и инвестирования инноваций (инновационное интрапренерство, со-инвестирование разработчиков и потребителей), новых взаимосвязей предпринимательских структур (блокчейн и «смарт-контракт»).

Таким образом, развитие технологической конвергенции видоизменяет структурные сдви- ги, расширяя границы отраслевых производств, меняя рыночные условия будущей релокации инвестиционных потоков, отраслевых производств, территориального размещения производительных сил - факторов структурного сдвига. При этом само-индуцирование конвергентных технологий, их способность быстро капитализироваться и расширять долю использующих их отраслей в структуре экономики связано с взаимопроникновением и рекомбинированием технологических инноваций, разрабатываемых в разных технологических платформах, но способных дать общий продукт. Поэтому структурные сдвиги, индуцированные технологической конвергенцией, сопровождаются развитием экономических отношений, регулирование которых государством прежними инструментами (госинвестиции, инновационное налоговые льготы, субсидии) не приведет к желаемому эффекту, но может вызвать обратный результат.

\section{Библиографический список}

1. Белоглазова С.А. Развитие нанотехнологических кластеров как элементов инфраструктуры наноиндустрии: Европейский опыт // Вестник ВолГУ. Серия 3: Экономика. Экология. 2015. № 1. С. 22-29.

2. Блокчейн (мировой рынок). Информационный портал «Государство. Бизнес. IT». URL: http://www.tadviser. ru/index.php/Статья: Блокчейн_\%28мировой_рынок\%29 (дата обращения: 26.06.2019).

3. Ветлуги К. Что такое НБИК? // В мире нано. 2010. № 3. С. 11-12.

4. Гасанов М.А., Гасанов Э.А. Структурная конвергенция в экономике России и ее ограничения // Вестник Томского государственного университета. Экономика. 2014. № 1 (25). С. 5-16.

5. Дубинина М.Г. Влияние информационных технологий на динамику занятости в России и за рубежом // Наука. Инновации. Образование. 2017. № 2 (24). С. 37-46.

6. Елхина И.А. Мониторинг структурных сдвигов в экономике регионов России в условиях развития конвергентных технологий: Автореф. дис. ... канд. эконом. наук.- Волгоград: ВолГУ, 2017. 26 с.

7. Как инвестировать в самые прорывные технологии по версии МІТ. Информационно-аналитическое агентство «РБК». URL: https://www.rbc.ru/money/15/03/2017/58c949269a7947dabf976811 (дата обращения: 26.06.2019).

8. Кастельс М. Информационная эпоха. Экономика, общество и культура. M.: Blackwell, 2000. 608 c.

9. Лиллевяли Г. Куда вложиться завтра. Пять инвестиционных идей глобального рынка //Forbs. 10.11.2017.URL: http://www.forbes.ru/finansy-i-investicii/352651-kuda-vlozhitsya-zavtra-pyat-investicionnyh-idey-globalnogorynka (дата обращения: 26.06.2019).

10. Настала эра когнитивных технологий. Интернет-портал компании IBM.URL: https://www.ibm.com/cognitive/ ru-ru/ (дата обращения: 26.06.2019).

11. Национальное информационное агентство «Вести». Объем мирового рынка биотехнологий превысил $\$ 1$ трлн. 16.06.2015. URL: https://www.vestifinance.ru/articles/58758 (дата обращения: 26.06.2019).

12. Обзор рынка биотехнологий в России и оценка перспектив его развития. M.: Frost \& Sullivan, 2014. С. 7-9.

13. Roco M.C., Bainbridge W.S. Converging technologies for improving human performance: nanotechnology, biotechnology, information technology and cognitive science. New York: Kluwer Academic Publishers, 2003. pp. 9. 